\title{
Creativity of International Development Strategies and Audit of Entities' Financial Management
}

\author{
Tetyana Calinescu \\ Finance Department \\ National Aerospace University \\ «Kharkiv Aviation Intuition» \\ Kharkiv, Ukraine \\ tetyana.calinescu@gmail.com \\ http://orcid.org/0000-0003-4919-5788
}

\author{
Ganna Likhonosova \\ Finance Department \\ National Aerospace University \\ «Kharkiv Aviation Intuition» \\ Kharkiv, Ukraine \\ a.likhonosova@gmail.com \\ http://orcid.org/0000-0001-6552-8920
}

\author{
Olena Zelenko \\ International Economy and Tourism \\ Department \\ Volodymyr Dahl East Ukrainian National \\ University \\ Severodonetsk, Ukraine \\ zelenko.olena@gmail.com \\ http://orcid.org/0000-0003-4880-246X
}

\begin{abstract}
The article presents the author's vision of the construction of creative international strategies for the development of forms of financial management of business entities. The creativity of behavioural finance in the article is based on the fact that the behaviour of the main shareholder turns out to be irrational, and the decisions made are contrary to the principles of rational behaviour of traditional finance. Therefore, the main factors, problems and conditions for designing of creative development strategies for business entities were identified. The authors singled out the fundamental blocks of financial management based on a creative approach that takes into account the reactions and behaviour of people, the manifestation of their psychological phenomena and sociological features of the society in which financial decisions are made. The originality of the research consists in the substantiation of international financial management strategies based on a creative approach, taking into account the factor of globalization. It was concluded that further practical application of the presented proposals of managing the business entity finances on the basis of behavioural aspects will significantly improve existing financial models and minimize the degree of influence of subjective factors in the different areas of financial management.
\end{abstract}

Keywords - creativity, international strategies, development, audit, financial management.

\section{INTRODUCTION}

The current model of economic development of Ukraine and its subjects of economy involves replacing the old paradigm of managing the country's economy to new priorities and technologies of development [1, pp. 17-23, pp. 52-55, pp. 78-147], which include creative mechanisms of modernization, structural adjustment and financial support of the national economy, economic entities and human capital. The processes of globalization and the proliferation of digital technologies also make adjustments to the question of preserving their identity, revision of relations between business entities in the domestic and foreign markets, establishing international cooperation, dialogue and strategy, increasing financial mobility, independence and security of different actors, national economy.

The expert, audit researches of social and economic processes of development of business entities in Ukraine and abroad are conducted [1, pp. 138-141, pp. 158-160], [2], [3, p. 24], author's research [4, pp. 234-257], [5] proved that there are several factors hampering the achievement of strategic priorities:

1. As a result, in the East of Ukraine national economies lose up to $25 \%$ of GDP every year;

2. The development of the shadow economy, which currently reaches half of the country's GDP;

3. Corruption, which reached $14 \%$ of GDP, contributes to the development of the shadow economy and the introduction of measures for business entities;

4. High energy intensity of the economy, which exceeds the indicators of developed countries in 3-5 times;

5. Inaccessibility of financial and investment resources due to devaluation processes occurring in the banking system;

6. The loss of creative human capital due to inefficiently implemented socio-economic policies in the state, which contributes to increased external migration of the population, reduction of population and its economically active composition [2, p. 23]; an unfair distribution of national wealth that generates inconsistencies in society and the unsalability of workers.

\section{INDICATORS CHARACTERIZING CREATIVITY}

Among indicators that characterize creativity determine: political and social structure; originality; variety, viability; openness, trust, tolerance and accessibility; entrepreneurship, research and innovation; strategic leadership, talent and ability to study; communication, communication and work on the Internet; place of residence, standard of living and well-being, professionalism and efficiency. The presence of these factors allows attracting and retaining creative workers in the work force, creating conditions for the growth of the share of creative education, receiving high incomes, open to ideas social space, high technological level and developed infrastructure, and, at the same time, imposing requirements for high professional training of workers [1], [6, p. 121]. Drivers of the growth of the creative industry are the latest technology and demand for creative products [7]. 
An audit of the development of the creative industry should be carried out according to official statistical indicators that are in line with the European and international standards of assessment, which will allow comparative studies of the development of the domestic creative sphere and other countries of the world. As such, we can propose the 17 priorities of sustainable development proposed by the UN General Assembly [3, pp. 23-24]. Moreover, all of them are part of the UN Research Programs, which determine the levels of socio-economic development of countries around the world, and therefore adapted to all audit procedures and statistical analytical comparisons used in international practice. However, modernization of statistical support of the creative industry is necessary. It is necessary to form a single register of forms of organizations of creative business of economic entities, to establish cooperation with state structures and international organizations.

Regarding the financial and economic development of creativity in Ukraine, it is characterized by the absence of effective mechanisms of public or private financing, cofinancing of creative projects, complicating the possible participation of domestic projects in EU grant applications, lack of motivation for foreign and domestic investors, which does not contribute to the creation of creative production and development in any sphere of activity of business entities [8, $\mathrm{p}$. 4]. Therefore, the solution of these problems requires the development and implementation of a comprehensive policy for modernizing the national economy based on the enhancement of all creative potential, which includes: reforming the legislation in the area of developing the priorities of creativity; assistance in the formation of creative business and various accelerators for the dissemination of successful practices, increasing communicative skills in attracting human capital and protecting copyright; formation of open educational professional networks for popularization and support of the domestic creative product; strategy and taking into account the risks of creative development and commercialization of goods and services.

\section{BusINESS CYCLE TURBULENCE}

Practically throughout its history, Ukraine's economy has experienced multi-scale shocks. However, these trends are inherent not only in Ukraine's young, not mature economy, but also in countries that dictate the conditions for development of the world are also subject to market, unpredictable anomalies, unforeseen opportunistic shifts and global risks. All these trends of unpredictability and unpredictability are becoming a new economic reality, which is inherent in the criteria of a physical phenomenon - turbulence. However, the interpretation of this process is often based on an intuitive understanding of its meaning, rather than on a theoretically sound scientific base.

Turbulence is a physical phenomenon in which fractal and linear waves of various sizes arise spontaneously in a fluid or gas flow, resulting in the basic physical characteristics of the currents experiencing random fluctuations [9, p. 1494]. In other words, turbulence is an unordered movement, which is characterized by a rapid change in the pace of on-going processes with unpredictable consequences. The Oxford
Dictionary interprets turbulence as an unregulated mass due to the unpredictability of the behaviour of its individual elements [10, p. 1554]. In economics, turbulence can be represented as an unordered movement of elements of the economic system, a global transformation of economic processes, and, as a result, a strong fluctuation of economic indicators $[11$, p. 2].

In Ukraine, the influence of turbulence is becoming increasingly significant, and this process itself is not amenable to a clear diagnosis. If you do not take appropriate measures to balance, levelling negative trends, there is chaos, in which entrepreneurs, industries, markets, industries, governments are immersed.

From today's economic cycle and the stage of economic development, it is worth waiting for a significant number of multi-scale shocks that can cause increased risks and uncertainty both at the state level and for the average entrepreneur. Today, economic reality is becoming a succession of unexpectedly intermittent periods of economic well-being and recession, where chaos, risk and uncertainty prevail.

For any country, business entities play an important role, ensuring the process of reproduction in the state and the pace of socio-economic development of society. The volume of the gross national product and the fullness of the budget revenues as a whole largely depend on the successful business position of the state. The success of an individual enterprise depends largely on the effectiveness of financial and management decisions, as well as the flexibility of market strategies. This necessitates the objectivity of financial decisions and management of financial flows of business entities.

\section{A. Creative-based financial management units}

The creativity of behavioural finance is based on the fact that people's behaviour is often irrational, and the decisions made are contrary to the principles of rational behaviour of traditional finance. We can single out the fundamental blocks of financial management, based on a creative approach that takes into account the reactions and behaviour of people, the manifestation of their psychological phenomena and sociological features of a society in which financial decisions are made:

1. The effect of framing. In a general sense, a frame is a way of organizing representations stored in memory [9], cognitive model, scheme of cognitive representations. This is one of the psychological factors questioning the rationality of the traditional theory of financial management. Perspectives at risk are characterized by possible outcomes and probabilities of these outcomes. However, the same options can be formulated and perceived diametrically opposed. The perception of people's choices depends on how these options are presented.

Studies in the field of understanding and interpreting the language show that people quickly translate most of what they heard into the form of an abstract presentation, which does not consider and does not establish what was really said, but only what was meant, supposed and meant [9]. In other words, financial decisions are often made depending on how the 
question is presented and the object of financing, even if objectively the facts remain unchanged.

2. Heuristic errors. In modern conditions, a person has limited time and limited cognitive resources for decisionmaking, which makes it difficult to optimally analyse available data. To accelerate the speed of reaction to external stimuli, certain algorithms are developed - mental modules [12, p. 242], called heuristics in psychology. The concept of "heuristics" is defined as a method of analysing economic phenomena and processes, decision making based on intuition, resourcefulness, analogies, experience, ingenuity, based on the special properties of the human brain and a person's ability to solve problems for which a formal mathematical algorithm, an exact way of solving known [13, p. 318].

Heuristics are also called "short cuts" that simplify the complex methods of processing information that are required to make a judgment. On the one hand, heuristics can be extremely useful for solving a certain range of tasks, since they reduce the human need for the additional cognitive resources needed to solve a problem and facilitate data processing. On the other hand, heuristics lead to the emergence of preferences, and, accordingly, errors. A key doctrine of the traditional approach to financial management is that markets are able to eliminate errors resulting from deviations from rational behaviour. Some scientists suggest [14, p. 43] that people learn to avoid mistakes through experience and material incentives: as people learn, directly from investment professionals, or indirectly from their own experience, irrational behaviour should disappear from the market.

\section{COMPONENTS OF THE FORMATION OF A CREATIVE STRATEGY FOR THE DEVELOPMENT OF BUSINESS ENTITIES}

However, the development of different forms of creativity should take place on the basis of their coherent and complementary use, with support [6], [15], which promote, facilitate, provide accumulation of human capital, able to establish interaction between different subjects of management, providing a comprehensive training of participants to access new knowledge, which is a significant criterion for the success of cooperation in the development and implementation of creative strategies. Expected risks and deepening of socioeconomic imbalances in the development of regions should also be expected, which should be considered when developing new creative strategies for the development of business entities. But at the same time, creative strategy, financial support and its audit should be individual because each economic entity that uses creative technologies is unique, has its unique individual qualities that are characterized by indicators of economic potential (the ability to produce creative products) and its components (volume of material, labour, energy, money, information resources), level of technical support, used creative technologies, staffing of the employee management team, organizational culture, etc. [16, p. 7]. The main components of the formation of a creative strategy for the development of business entities must become [17]:

- audit of business environment, revealing of problem aspects and their analysis;
- identification of changing tendencies in the external and internal operating environment;

- identify strengths and weaknesses, threats and new business opportunities;

- formation of the strategy of the entity's activity: definition of the strategic and tactical goals, definition of priorities and development of the indicators system;

- monitoring of real indicators and identifying deviations from goals and objectives; control of financial liabilities, cash and material flows of an entity;

- audit of managerial decisions;

- changing strategy and adjusting enterprise plans.

\section{A. Principles of decision making for managing a financial entity based on a creative approach}

On the basis of this, it is possible to formulate the basic principles of decision-making of the management of finances of a business entity on the basis of a creative approach:

1. Certainty is the lack of certainty. Both with uncertainty and risk, results are unknown. But with uncertainty, we do not know how the results will be distributed, and at risk, we are well aware of how this distribution looks. Here, a behavioural problem such as overconfidence arises. Studies show that people are often overly confident in their abilities and predictions. As a result, they tend to predict possible results in a very narrow range.

It is extremely important to consider the uncertainty factor in financial management. Numerous stories about the destruction of hedge funds boil down to the fact that the fund manager arrogantly overestimated any investments and invested too much money in them. When placing capital, portfolio managers must consider the fact that unforeseen events do occur.

2. Financial decisions are derived from weighting probabilities. Specifying this principle, it is necessary to detail another concept from the field of behavioural finance: the fear of loss. For quite reasonable evolutionary reasons, people tend to avoid losses when choosing between risky outcomes. In other words, the negative impact of a loss on the human psyche is two and a half times stronger than the positive impact of profits of the same size. Human psychology is so arranged that he likes to be right, so he often makes a choice in favour of events with a high probability.

The emphasis on probability is reasonable when outcomes are symmetrical, but impractical when winnings are asymmetrical. It is known that approximately $90 \%$ of all positions on options lose money. Does that mean holding options is a bad idea? The answer depends on how much money you earn on those $10 \%$ positions that turn out to be profitable. If you buy 10 options for $\$ 1$ and lose money on nine of them, but one brings in $\$ 25$, then you will have quite a decent profit if you have an appallingly low success rate. That is why, in terms of expected value, some positions with a low 
probability can be very attractive, and some positions with a high probability are not.

3. Make financial management decisions more efficiently in the face of uncertainty. Most financial management decisions are made on the basis of imperfect, irrelevant or incomplete information, however, these solutions should also contain a critical analysis of the information available.

Russo and Schoemaker in their research point out a common misconception that more information allows us to more accurately predict the future and improve decisionmaking [18]. However, in fact, additional information often only complicates the decision-making process (Figure 1). The illustration shows that more information does not always mean more accuracy in making financial decisions.

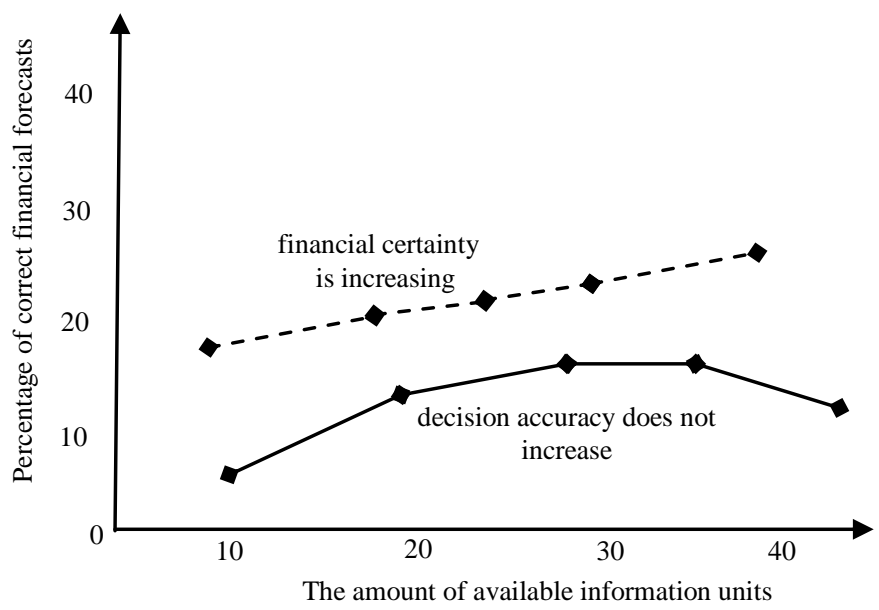

Fig. 1. The ratio of the amount of information and accuracy of financial forecast

Source: authoring based on [18]

4. Financial decisions are evaluated from the standpoint of the method of their adoption. A reasonable financial process is one in which the price is carefully considered relative to the expected value [19]. At the same time, high-quality feedback and continuous training allow financial managers to improve their decision-making process.

Modern processes of globalization are unique in terms of trends and processes of economic development for business entities operating in the international market allowing to allocate several creative strategic approaches for the financial resource management:

I. Information development Strategy for the business entity. The changes in the production structure has become a hallmark for the post-industrial era. A significant role in these processes is played by the informatization of economic processes at both micro- and macro levels. Information appears as the resource necessary for production and as the final product of economic activity. Expression "who owns information, owns the world" is more than ever relevant. Therefore, according to such a strategic approach, the business entity involves the formation of a modern information field, which will ensure the adoption timely financial decisions in accordance with the current situation.

II. Strategy of counteraction to cyclic development, or socalled anticyclic strategy. The cyclical processes of economic development have been proved long time ago by theoretical science and world economic practice. These trends are most pronounced in those countries that are in an intensive development phase. The typology of cycles is very diverse, but most often they are considered in terms of duration: long-term, medium-term and short-term cycles of economic development. The activities of individual economic entities at the international level are most affected by medium-term cycles, in which the crisis phases affect the financial position of most economic operators (even when the company operates only in the domestic country market). The last most tangible global crisis was the financial crisis of 2008-2009, during which all countries and the world monetary-financial systems were reacted. According to the second strategic approach to financial activity, the main task is to anticipate the future crisis and to develop a set of preventive measures that will allow the business entity to minimize the impact of destructive phenomena in the system of financial and economic relations.

III. Strategy for targeting small and medium-sized businesses. According to experts [20, pp. 353-354], at the beginning of the XXI century, the share of small and medium business sector production in the GDP of the world leading countries amounted to more than $50 \%$ (USA - 52\%, Japan $53 \%$, Italy $60 \%$, etc.). So, for this reason, in many countries of the world, the development of small and medium-sized enterprises is supported at the state level by granting preferences, tax breaks, etc. Thus, the shredding of capital and migration from large to medium and small business will contribute to the stabilization of the financial and economic situation for business entity in both nationally and internationally level.

IV. The strategy of investing in the creative industry. The origins of this concept are laid in 30-40 years of the last century. The real recognition of the creative economy and creative industries took place at the turn of the twentieth and twenty-first century, when in 1998 in Great Britain started to develop the creative industries as the priority directions of the country's economy and consolidated it at the legislative level [21, p. 154]. According to world tendencies, for today the grouping of countries has done not on the basis of belonging to one or another branch of industry, but on the basis of the stage of industrial and post-industrial development. The presence of a creative economy developed is a characteristic feature for post-industrial countries of the world. The basis of the creative industry is the small and medium enterprises that produce a creative product, designed not only for domestic consumption but also for export. The creative industry includes: show business, cinema and theatre, fine arts, design, etc. In most developed countries, during the period of transformation and the transition to a post-industrial development stage, the creative industry has become a "lifeblood" for abandoned industrial objects, which were given a second life as a creative space for creativity and self-realization for creative 
personalities. Economically justified real or financial investment in creative economy objects is a strategic investment in the financial stability of the business entity in the long run.

The last proposed strategic approach for ensuring financial stability of business entities is especially relevant for Ukraine, because the creative economy sector in our country is only starting to develop and there is a real opportunity to take its own niche for the production of a unique creative product that will be in demand at the international level.

The activity of any entity is determined by internal and external factors. Therefore, it is necessary to continuously analyse and audit the business environment in order to identify the main trends of change, because creative business must adapt quickly to changes in the environment: in politics, economy, society, technology, without which it is impossible to provide further development. The revealed tendencies should complement and correct the strategies of business entities in conditions of instability, internal and external competition, fluctuations in demand and supply on creativity, acceleration of scientific and technological progress and the need for rapid responses to globalization challenges. Of course, only very large companies can have a significant impact on creative products markets, strategies, audits and creative technologies of development promoted by all well-known foreign experts [22], [23], [24], but for other business entities, the best way is to study situations that allow you to adapt to the problems that surround them and bring them back in their favour for maximum benefit.

\section{CONCLUSIONS}

To sum it up, it should be noted that the development of creative entrepreneurship, interaction with small and mediumsized businesses, the interrelation of individual strategies with national and international programs can be the driving force that will achieve the main socio-economic priorities in the state and make them effective and successful, not only individual economic entities, but also the country as a whole.

In the context of the Ukrainian economy, behavioural finance research is still at an early stage, however, in practice, certain elements of behavioural finance are often manifested in the national financial system: from the decisions of an individual investor in the financial market, or the financial decisions of a large bank's management. Thus, a deeper study of the theory and practice of financial management based on the behavioural aspects of the main groups of participants in the financial system will significantly improve existing financial models and minimize the degree of influence of subjective factors in the areas of financial management, trading, business valuation and encouragement of independent financial decisions.

The team of authors at the Finance Department of the National Aerospace University "Kharkov Aviation Institute" in cooperation with well-known and famous scientists from other Universities of Ukraine created a powerful joint scientific platform for generating ideas and research in the field of behavioral finance in crisis phenomena and their consequences for Ukraine. Therefore, the presented materials and theoretical discussions are copyrighted with the refinement of a personal research position.

\section{REFERENCES}

[1] Ukraine 2030: Doctrine of balanced development. Lviv: Calvary, 2017.

[2] "People. Economy. Security", Business, December, pp. 22-23, 2018.

[3] "When social responsibility of corporations is not enough", Business, October, pp. 22-24, 2018.

[4] Democratic mechanisms of self-sufficiency of socio-economic transformations in society, sciences edit T. Calinescu, Severodonetsk: V. Dahl East Ukrainian National University, 2018.

[5] T. Calinescu, G. Likhonosova, and O. Zelenko, "Mechanism of Transformation Socio-Economic Potential of Ukraine: Tearing Away and Social Dialogue", in Proc. 32nd International Business Information Management Association Conference (IBIMA), Seville, Spain, 2018, pp. 949-965.

[6] S. Shchegljuk, "Features of the development of the creative industry of Ukraine: perspective forms of spatial organization". Socio-economic problems of the modern period of Ukraine, vol. 6, no. 128, 2017.

[7] J. Kloudova, "The Impact of the Development of a Creative Economy on Economically Late Regions", Journal of the New Economic Association, no. 5, pp. 109-124, 2010.

[8] Indicators of cultural influence on development. Brief analytical review of Ukraine, 2017. [Online]. Available: http://www.culturepartnership.eu/upload/editor/2017/Policy\%20Briefs/ Abr-lv_C\&C_photo_UA.pdf. Accessed on: June 25, 2019.

[9] V. Buzel, "Great Dictionary of Contemporary Ukrainian Language", Kyiv; Irpin: "Perun”, 2009.

[10] Concise Oxford English Dictionary. By editors C. Soanes, A. Stevenson. New York: Oxford University Press, 2009.

[11] V. Burlachkov, "Turbulence of Economic Processes: Theoretical Aspects", Economy Issues, no. 11, p. 90, 2009.

[12] T. Calinescu, G. Likhonosova, G. Nadion, and S. Kilinkarov, "Selforganization of enterprises: tendencies of economic socialization". Luhansk: V. Dahl East Ukrainian National University, 2012.

[13] B. Raizberg, L. Lozovsky, and E. Starodubtseva, Modern Economic Dictionary. Moscow: INFRA-M, 2006.

[14] A. Ostrovskaya, "Development of behavioral finance in a turbulent economy", in Proc. of the 3ht Intern. scientific conf. Actual problems of economics and management, Moscow, 2015, pp. 43-46.

[15] O. Valevsky, "Current issues of legal protection of cultural policy: an analogous note", The National Institute for Strategic Studies, 2017. [Online]. Available: http://www. http://old2.niss.gov.ua/content/articles/files/kultur_polityka-845b5.pdf. Accessed on: June 20, 2019.

[16] M. Pushkar, "Creative Region (information for management)". Ternopil: Carte blanche, 2006.

[17] T. Storozhuk, "Strategic accounting in the enterprise information system by business", Lviv: Polytechnic National University Institutional Repository. [Online]. Available: http://old2.niss.gov.ua/content/articles/files/kultur_polityka-845b5.pdf: Accessed on: June 21, 2019.

[18] J. Russo, P. Schoemaker, Winning Decisions: Getting It Right the First Time. New York: Currency/Doubleday, 2002.

[19] O. Yanitsky, "Turbulent Times": a Slogan or a Problem of Sociology?" Social Sciences and Modernity, no. 6, pp. 155-164, 2011.

[20] S. Sokolenko, "Globalization and Security of Ukraine". Kyiv: Logos, 1999.

[21] Kh. Loshkovska, "Creative Industries as the most important segment of strategic development", Actual problems of international affairs, vol. 119 (part II), pp. 153-158, 2014

[22] B. Ryan, Strategic Accounting for Managers. Moscow: Audit, 1998.

[23] I. Ansoff, Strategic Management. Moscow: Economy, 1989.

[24] R. Ackoff, Planning for the Future of a Corporation. Moscow: Progress, 1985. 